\title{
ANALISIS KINERJA SISTEM PENGOLAHAN DATA BERBASIS WEB MENGGUNAKAN IT BALANCED SCORECARD SEBAGAI SARANA UNTUK MENUNJANG KINERJA PEGAWAI PADA BADAN PUSAT STATISTIK (BPS) KABUPATEN SRAGEN
}

\author{
Damai Yanti Nainggolan ${ }^{1}$, Agustinus Fritz Wijaya ${ }^{2}$ \\ ${ }^{1,2}$ Fakultas Teknologi Informasi, Universitas Kristen Satya Wacana
}

\section{Article Info:}

Dikirim: 23 April 2019

Direvisi: 25 Mei 2019

Diterima: 28 Mei 2019

Tersedia Online: 29 Juni 2019

Penulis Korespondensi: Damai Yanti Nainggolan Universitas Kristen Satya Wacana, Salatiga, Indonesia

Email: author@sitech.ac.id

\begin{abstract}
Abstrak: Sistem pengolahan data adalah salah satu sistem berbasis web yang dibuat oleh BPS Pusat untuk memfasilitasi pegawai BPS Kabupaten Sragen agar dapat membantu, dan mempercepat pekerjaannya dalam hal mengolah data. Penelitian ini bertujuan untuk melihat bagaimana upaya yang dilakukan oleh BPS Kabupaten Sragen dalam memanfaatkan sistem dan teknologi informasi yang ada. Penelitian ini menggunakan metode kualitatif, dan menggunakan 4 Perspektif (Perspektif Kontribusi Perusahaan, Perspektif Orientasi Pengguna, Perspektif Penyempurnaan Operasional, dan Perspektif Orientasi Masa Depan) pada IT Balanced Scorecard untuk melihat pemanfaatan Teknologi Informasi yang dilihat dari kualitas kinerja pegawai pada BPS Kabupaten Sragen. Hasil dari penelitian ini adalah perlu adanya perbaikan pada Perspektif Orientasi Pengguna, dan Perspektif Orientasi Masa Depan terkait SDM dan juga layanan SI/TI yang digunakan untuk menunjang kinerja pegawai BPS Kabupaten Sragen.
\end{abstract}

Kata kunci: sistem pengolahan data; IT balanced scorecard; BPS kabupaten sragen.

\begin{abstract}
Website-based data management system is a system that created by Center of Indonesian Central Board of Statistics to facilitate employees of Indonesian Central Board of Statistics Sragen Regency to help and accelerate their work in terms of data managing. The purpose of this research is to know how Indonesian Central Board of Statistics Sragen Regency's efforts to utilizing information system and technology exist. This research uses qualitative method and four Perspectives (Perspective of Corporate Contributions, User Orientation Perspective, Operational Improvement Perspective, and Future Orientation Perspective) on the IT Balanced Scorecard to know information technology utilization that reviewed from the quality of employee performance in Indonesian Central Board of Statistics Sragen Regency. The results of this research are there needs to be an improvement in the User Orientation Perspective and Future Orientation Perspective related to human resources and IS/IT services that are used to support the Indonesian Central Board of Statistics Sragen Regency's employee performance.
\end{abstract}

Keywords: data management system; IT balanced scorecard; BPS sragen regency. 


\section{PENDAHULUAN}

Teknologi Informasi dan Sistem Informasi dari waktu ke waktu semakin berkembang dengan begitu pesat, begitu pula juga dengan data dan informasi statistik. Data dan informasi statistik seiring berjalannya waktu pasti juga akan berubah. Hampir semua tingkat pemerintahan menggunakan data dan informasi statistik sebagai acuan untuk melakukan perumusan kebijakan, perencanaan, pemantauan, dan evaluasi pembangunan. Badan Pusat Statistik (BPS) adalah Lembaga Pemerintah Non-Kementrian yang bertanggung jawab langsung kepada Presiden. BPS terdiri dari dua instansi vertikal (BPS Provinsi dan BPS Kabupaten atau Kota), salah satunya adalah BPS Kabupaten Sragen. BPS Kabupaten Sragen adalah sebuah instansi yang bersifat vertikal, yang berada dibawah dan bertanggung jawab kepada Kepala BPS Provinsi. BPS bergerak dibidang survei dan sensus penduduk, yang mempunyai tugas untuk menyediakan data dan informasi statistik yang terpercaya bagi semua pengguna yang memerlukannya.

BPS Kabupaten Sragen tidak luput dari perkembangan Teknologi Informasi dan Kominikasi (TIK), mereka selalu berusaha untuk mengikuti perkembangan tersebut, agar tidak ketinggalan, dan juga dapat bersaing dengan perusahaan lain. Dalam mengikuti perkembangan tersebut, BPS Kabupaten Sragen selalu berupaya untuk menjaga dan meningkatkan kualitas layanan Sistem Informasi (SI) / Teknologi nformasi (TI) yang mereka miliki. Di BPS ada beberapa macam layanan TIK untuk menunjang pelayanan maupun pekerjaan yang dibutuhkan oleh pegawai maupun pengguna data dan informasi statistik, yaitu: 1) E-mail BPS, yaitu @bps.go.id yang digunakan pegawai BPS Kabupaten Sragen untuk memudahkan dalam berkomunikasi terkait aktivitasaktivitas yang dikerjakan, baik antara Kepala dengan pegawai, ataupun sebaliknya. 2) Portal Resmi BPS, yaitu https://sragenkab.bps.go.id yang digunakan BPS Kabupaten Sragen untuk menampilkan informasi dan data statistik yang valid supaya masyarakat dapat mengakses dengan mudah dan cepat informasi atau data yang mereka inginkan. 3) Contac Center, yaitu Telp (0271) 891151, Fax (0271) 894266, dan e-mail bps3314@bps.go.id yang digunakan untuk menampung semua aspirasi pengguna atau masyarakat terkait pelayanan yang diberikan oleh BPS Kabupaten Sragen. BPS Kabupaten Sragen sudah berupaya untuk menjaga dan meningkatkan kualitas layanan SI/TI yang mereka miliki, tetapi kinerja kualitas layanan dan pelayanan perlu ditingkatkan lagi supaya dapat menghadapi dan mengantisipasi perubahan-perubahan yang akan terjadi dimasa mendatang, begitu pula juga dengan kinerja pegawai. Kinerja pegawai juga perlu di tingkatkan juga, karena kinerja pegawai sangat berpengaruh bagi perusahaan untuk kedepannya. Penelitian ini dilakukan untuk menganalisis kinerja sistem di BPS Kabupaten Sragen dengan menggunakan kerangka IT Balanced Scorecard yang mempunyai 4 perspektif didalamnya, diantaranya adalah 1) Perspektif Kontribusi Perushaan, 2) Perspektif Orientasi Pengguna, 3) Perspektif Penyempurnaan Operasional, dan 4) Perspektif Orientasi Masa Depan, untuk mengetahui seberapa besar tingkat pemanfaatan SI/TI yang digunakan, dilihat dari kinerja pegawai BPS Kabupaten Sragen itu sendiri.

\section{TINJAUAN PUSTAKA}

\subsection{Penelitian Terdahulu}

Penelitian pertama yang sudah pernah dilakukan sebelumnya yang berjudul "Analisa Kinerja Sistem Informasi/Teknologi Informasi Pada BPPT dan PM Kota Salatiga Menggunakan Kerangka IT Balanced Scorecard". Penelitian ini dilakukan di Badan Pelayanan Perizinan Tertentu dan Penanaman Modal (BPPT \& PM) di Kota Salatiga. Penelitian ini dilakukan untuk menganalisa kinerja SI/TI pada BPPT dan PM Kota Salatiga, dengan menggunakan kerangka IT Balanced Scorecard, dan menggunakan pendekatan deskriptif kuantitatif untuk pengumpulan data, data yang diperoleh dari kuesioner, wawancara, dan observasi. Hasil dari penelitian ini adalah Perspektif Kontribusi Perusahaan yang hasilnya paling rendah, karena penerapan aplikasi yang belum efektif dan efisien sebab pegawai masih banyak yang menggunakan proses manual, serta dalam menggunakan dana masih belum efektif [1].

Penelitian kedua yang sudah pernah dilakukan sebelumnya yang berjudul "Analisis Kinerja SI/TI Pada PDAM Kota Salatiga Menggunakan Kerangka IT Balanced Scorecard". Penelitian ini dilakukan di PDAM Kota Salatiga, yang beralamat di Jalan Letnan Jendral Sukowati No. 66/70, Kalicacing, Sidomukti yang bergerak di bidang penyediaan air bersih. Penelitian ini dilakukan untuk menganalisis kinerja SI/TI pada PDAM Kota Salatiga, dengan menggunakan kerangka IT Balanced Scorecard, dan menggunakan pendekatan kualitatif untuk pengumpulan data, data yang didapat dari hasil wawancara dan observasi. Pada penelitian ini ditemukan beberapa temuan yang harus diperbaiki, yaitu jaringan, aplikasi, Evaluasi yang belum dilakukan secara optimal, SOP yang belum diperbaharui, dan perlu dilakukan training yang maksimal agar dapat memahami dan menggunakan aplikasi [2].

Penelitian ketiga yang sudah pernah dilakukan sebelumnya yang berjudul "Analisis Kinerja Sistem Informasi dan Teknologi Informasi untuk Menunjang Kinerja Karyawan Menggunakan Framework IT Balanced Scorecard pada Wi-Fi Universitas Kristen Satya Wacana". Penelitian ini dilakukan di salah satu kampus di Salatiga, yaitu UKSW (Universitas Kristen Satya Wacana). Penelitian ini dilakukan untuk menganalisis kinerja dari SI/TI pada Wi-Fi UKSW, dengan menggunakan kerangka IT Balanced Scorecard, dan menggunakan 
metode penelitian kualitatif untuk pengumpulan data, data yang didapat dari hasil wawancara dan observasi. Pada penelitian ini ditemukan beberapa hal yang harus ditangani, yaitu penambahan SDM (Sumber Daya Manusia) untuk dapat membantu kinerja dari Wi-Fi UKSW untuk menangani complain maupun untuk membantu dalam menyelesaikan proyek karena Wi-Fi UKSW selalu dibutuhkan dan digunakan oleh semua civitas akademika UKSW, serta perlu adanya evaluasi dan upgrade terhadap sistem untuk memonitoring $W i-F i$ UKSW [3].

Penelitian ini mengacu pada penelitian sebelumnya atau terdahulu, yaitu sama-sama menganalisis tentang kinerja dari sebuah Sistem Informasi dengan menggunakan 4 perspektif yang ada pada kerangka IT Balanced Scorecard. Pada penelitian ini lebih mengarah pada masalah kinerja dan kepuasan pegawai. Pada penelitian ini, peneliti melakukan penelitian sekaligus melakukan KP (Kerja Praktek) di BPS Kabupaten Sragen. Keistimewaan pada penelitian yang dirasakan oleh peneliti adalah dapat melihat langsung pekerjaan apa saja yang dilakukan di ruang lingkup BPS Kabupaten Sragen, dan juga dapat ikut membantu dan merasakan bagaimana rasanya terjun langsung ke lapangan pekerjaan, serta dapat mengikuti kegiatan pelatihan yang diselenggarakan oleh BPS Kabupaten Sragen.

\subsection{IT Balanced Scorecard}

IT Balanced Scorecard merupakan serangkaian pengukuran kinerja untuk perushaan yang diukur menggunakan 4 perspektif yang terdapat pada IT Balanced Scorecard, yaitu Perspektif Orientasi Pengguna, Perspektif Kontribusi Perusahaan, Perspektif Operasional, dan Perspektif Orientasi Masa Depan. IT Balanced Scorecard mempunyai tujuan supaya pengguna dapat menyesuaikan perencanaan dan aktivitas pada sistem informasi sebagai kebutuhan organisasi, menyediakan pengukuran untuk mengevaluasi efektivitas sistem informasi, meningkatkan kinerja sistem informasi, dan pencapaian hasil yang seimbang di antara Stakeholder.

Tabel 1. Perspektif dalam IT balanced scorecard

\begin{tabular}{|c|c|}
\hline User Orientation & Business Contribution \\
\hline How do users view the IT Department? & How does management view the IT department? \\
\hline Mission & Mission \\
\hline $\begin{array}{l}\text { To be the preferred supplier of information } \\
\text { system }\end{array}$ & $\begin{array}{l}\text { To obtain a reasonable Business Contribution } \\
\text { from IT }\end{array}$ \\
\hline Objectives & Objectives \\
\hline a. Preferred supplier of applications & a. Control of IT expenses \\
\hline $\begin{array}{l}\text { b. Preferred supplier of vs proposer of best } \\
\text { solution }\end{array}$ & $\begin{array}{l}\text { b. Business value of IT project } \\
\text { c. Provision of new business capabilities }\end{array}$ \\
\hline $\begin{array}{l}\text { c. Partnership with users } \\
\text { d. User satisfaction }\end{array}$ & \\
\hline Operation Excellence & Future Orientation \\
\hline $\begin{array}{l}\text { How effective and efficient are the IT } \\
\text { processes? }\end{array}$ & $\begin{array}{l}\text { How effective and efficient are the IT processes? } \\
\text { Mission }\end{array}$ \\
\hline $\begin{array}{l}\text { Mission } \\
\text { To deliver effective and efficient IT } \\
\text { applications and services }\end{array}$ & $\begin{array}{l}\text { To develop opportunities to answer future } \\
\text { challenges } \\
\text { Objectives }\end{array}$ \\
\hline Objectives & a. $\quad$ Training and education of IT staff \\
\hline a. Efficient and effective developments & Expertise of IT staff \\
\hline b. Efficient and effective operations & Research into emerging technologies \\
\hline & d. Age of application portofolio \\
\hline
\end{tabular}

Tabel 1 merupakan tabel 4 Perspektif yang ada pada IT Balanced Scorecard, yaitu 1) Perspektif Orientasi Pengguna (Perspective User Orientation), yaitu perspektif yang digunakan untuk mengevaluasi IT berdasarkan pandangan pengguna bisnis (pelanggan) itu sendiri bahkan lebih lagi dari pelanggan ke unit bisnis yang ada. 2) Perspektif Kontribusi Perusahaan (Perspective Business Contribution), yaitu perspektif yang digunakan untuk mengevaluasi kinerja Departemen TI berdasarkan pandangan dan manajemen eksekutif, para direktur, dan stakeholder. Evaluasi TI sendiri terbagi dari dua macam, yaitu jangka panjang, dan jangka pendek. Jangka panjang melihat dan mengevaluasi orientasi pada proyek dan fungsi IT itu sendiri, sedangkan jangka pendek melihat dan mengevaluasi finansial dari suatu perusahaan. 3) Perspektif Penyempurnaan Operasional (Perspective Operation Excellence), yaitu perspektif yang digunakan untuk menilai kinerja TI berdasarkan efektivitas dan efisiensi dari proses-proses IT yang dinilai oleh pihak manajemen. 4) Perspektif Orientasi Masa Depan (Perspective Future Orientation), yaitu perspektif yang digunakan untuk menilai kinerja TI berdasarkan cara pandang departemen TI itu sendiri terhadap tantangan di masa depan, serta kemampuan perusahaan dalam 
menghadapi tantangan di masa depan juga harus selalu direncanakan dengan cara membuat langkah-langkah atau strategi dalam mengantisipasi perubahan-perubahan yang akan terjadi di masa yang akan datang.

\section{METODOLOGI PENELITIAN}

Penelitian ini dilakukan di sebuah instansi yang berada di Kota Sragen, yaitu BPS Kabupaten Sragen. BPS Kabupaten Sragen adalah sebuah instansi yang bergerak dibidang survei dan sensus penduduk, beralamat di Jalan Letjen Suprapto, Kebayan 2, Sragen Kulon, Sragen, Jawa Tengah. Penelitian yang dilakukan ini menggunakan pendekatan deskriptif kualitatif, yaitu dengan cara melakukan wawancara dan observasi untuk mendapatkan data dan infromasi yang diperlukan. Data dan informasi yang didapat dari hasil wawancara dan observasi nantinya bertujuan untuk mengetahui data umum yang ada didalam BPS Kabupaten Sragen, seperti profil perusahaan, visi, misi, dan strategi perusahaan yang berguna untuk memperkuat penelitian yang akan dilakukan nantinya. Narasumber yang berpartisipasi dalam penelitian ini adalah Bapak Toga Hamonangan, S.Si, MM selaku Kepala di BPS Kabupaten Sragen dan 4 orang pegawai, yaitu Bapak Eko Wiyono, S.ST, M.Si selaku Kepala Seksi IPDS (Integrasi Pengolahan dan Desiminasi Statistik), Mbak Wahyu Eka Ningsih, A.Md selaku Bendahara, Mbak Muhit Nur Hidayah, S.ST selaku Staf Produksi, dan Bapak John Jaya Abdillah, S.ST selaku Staf IPDS. Penelitian ini lebih memfokuskan pada pegawai di BPS Kabupaten Sragen, yaitu mendeskripsikan kinerja dari pegawai itu sendiri, kedalam 4 perspektif dari IT Balanced Scorecard. Penelitian yang dilakukan, diselesaikan melalui tahapan penelitian yang terbagi dari enam tahapan, yaitu 1) Menentukan topik penelitian, 2) Menentukan Tempat penelitian, 3) Studi Literatur, 4) Mengumpulkan data (Wawancara dan Observasi), 5) Menganalisis data, dan 6) Menyusun laporan tugas akhir.

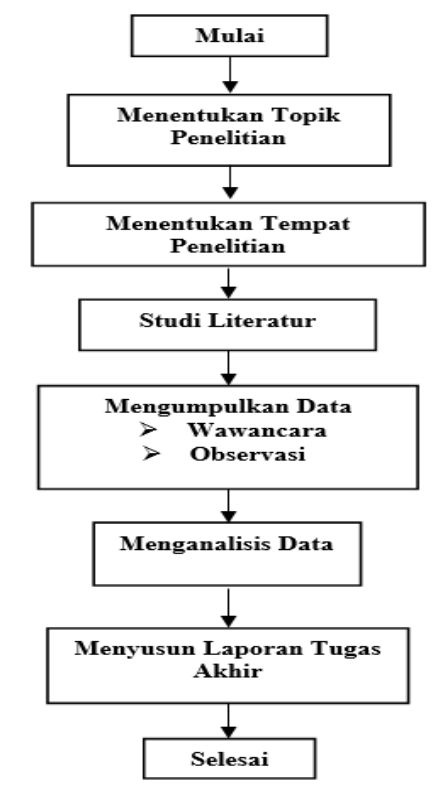

Gambar 1. Tahapan Penelitian

\subsection{Menentukan Topik Penelitian}

Tahap pertama yang dilakukan peneliti adalah menentukan topik penelitian, yaitu dimana peneliti menyiapkan, memikirkan dan menentukan topik yang akan dilakukan dalam penelitian, yaitu analisis kinerja sistem.

\subsection{Menentukan Tempat Penelitian}

Tahap kedua adalah menentukan tempat penelitian atau objek yang akan diteliti, yaitu dimana peneliti memikirkan, dan mentukan tempat penelitian untuk dilakukannya penelitian, yaitu BPS Kabupaten Sragen.

\subsection{Studi Literatur}

Tahap ketiga adalah studi literatur, yaitu dimana peneliti mencari dan mengumpulkan informasi maupun referensi teori yang relevan dengan penelitian yang dilakukan.

\subsection{Mengumpulkan Data}

Tahap keempat adalah mengumpulkan data, yaitu dimana peneliti terjun langsung ke tempat penelitian untuk melihat dan mengamati langsung objek yang diteliti (Observasi) dan melakukan tanya jawab kepada 
narasumber terkait informasi yang dibutuhkan (Wawancara), yaitu Kepala serta pegawai di BPS Kabupaten Sragen.

\subsection{Menganalisis Data}

Tahap kelima adalah menganalisis data, yaitu ketika dimana peneliti sudah mendapatkan data yang dibutuhkan, maka langkah selanjutnya adalah menganalisis data dari hasil observasi dan wawancara dengan menggunakan 4 perspektif yang ada dalam kerangka IT Balanced Scorecard yang digunakan sebagai acuan dalam menyusun hasil dan pembahasan.

\subsection{Menyusun Laporan Tugas Akhir}

Tahap keenam adalah menyusun laporan, yaitu dimana peneliti mulai menulis jurnal atau laporan tugas akhir mulai dari pendahuluan, tinjauan pustaka, metodologi penelitian, hasil dan pembahasan, hingga kesimpulan yang dihasilkan dalam penelitian.

\section{HASIL DAN PEMBAHASAN}

\subsection{Perspektif Kontribusi Perusahaan}

Pada Perspektif Kontribusi Perusahaan ini dilakukan penyelarasan dari Visi dan Misi pada BPS Kabupaten Sragen. Dalam mewujudkan Visi dan Misi tidaklah mudah karena diperlukan adanya upaya keras untuk dapat mencapainya. Visi dan Misi yang sudah dibuat tersebut diharapkan dapat dilaksanakan sesuai Visi dan Misi yang telah dibuat dan selalu melakukan evaluasi terhadap pelaksanaannya agar kedepannya dapat menjadi lebih baik. BPS Kabupaten Sragen mempunyai Visi menjadi "Pelopor data statistik terpercaya untuk semua", dan untuk mencapai Visi tersebut ada tiga Misi yang perlu dijalankan oleh BPS Kabupaten Sragen, yaitu 1) Menyediakan data statistik berkualitas melalui kegiatan statistik yang terintegrasi, berstandar nasional, dan internasional. 2) Memperkuat Sistem Statistik Nasional yang berkesinambungan melalui pembinaan dan koordinasi di bidang statistik. 3) Membangun insan statistik yang professional, berintegrasi, dan amanah untuk kemajuan perstatistikan. BPS Kabupaten Sragen juga menyusun sebuah Rencana Strategis 2015-2019 yang didasarkan pada pelaksanaan kinerja di Tahun 2015 yang dijadikan sebagai referensi bagi Kepala maupun pegawai di BPS Kabupaten Sragen dalam melakukan tugasnya. Rencana Strategis ini dibuat dengan harapan agar dapat lebih terarah, dan lebih mudah dalam mencapai sasaran, serta menjamin keberhasilan pelaksanaan dan mewujudkan Visi supaya dapat mencapai target dan sasaran pembangunan statistik yang telah ditetapkan. Upaya yang dilakukan BPS Kabupaten Sragen yaitu dengan cara meningkatkan kualitas dari data dan informasi statistik yang dihasilkan, meningkatkan kualitas dari pelayanan untuk memaparkan data statistik kepada pengguna yang membutuhkan data dan informasi statistik, dan meningkatkan kualitas dari proses tata kelola dalam perusahaan.

Untuk dapat mempercepat tersedianya data dan informasi statistik yang diperlukan oleh pengguna data, BPS Kabupaten Sragen menggunakan sebuah sistem yang berbasis website, yaitu website pengolahan data. Website pengolahan data dibuat oleh Biro Pengembangan Metoda bagian TI (Teknologi Informasi) di BPS Pusat, dan dijalankan menggunakan SOP yang sudah disusun oleh Pusat juga. SOP yang dibuat oleh Pusat juga berubah-ubah hampir setiap tahunnya, BPS Kabupaten Sragen hanya melihat dan menjalalankan apa yang sudah disusun oleh BPS Pusat, karena apa yang dikerjakan oleh BPS Kabupaten Sragen, itu juga yang dikerjakan oleh semua BPS Kabupaten yang ada di seluruh Indonesia. Berikut penuturan bapak Eko Wiyono selaku Kepala Seksi IPDS "Jadi, jika sistem tidak disusun oleh Pusat maka sistemnya akan berbeda-beda, dan juga akan menghasilkan suatu hasil yang berbeda pula. Oleh sebab itu, supaya tidak berbeda-beda yang membuat sistem adalah BPS Pusat itu sendiri. Sistem dibuatkan oleh Pusat juga atas dasar supaya BPS Pusat dapat melihat, mengevaluasi, dan memonitoring BPS yang yang ada di seluruh Indonesia. Dalam penggunaan sistem, pegawai hanya dapat menggunakannya sesuai tanggung jawab di bidang masing-masing, karena setiap pegawai memiliki password yang berbeda-beda untuk dapat login ke sistem tersebut.

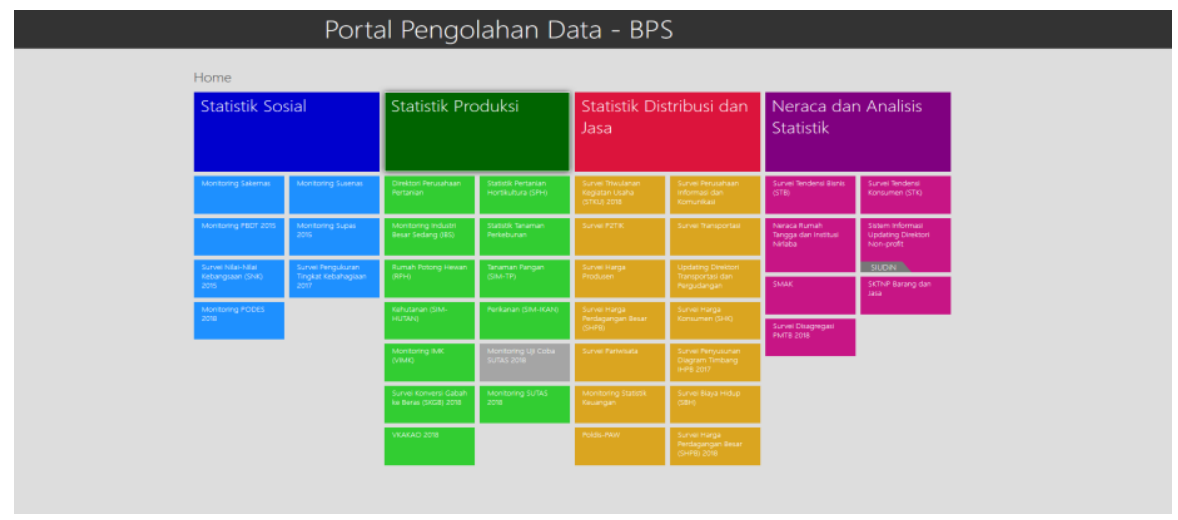

Gambar 2. Website Pengolahan Data 
Untuk meningkatkan kualitas dan maintenance operasional, BPS Kabupaten Sragen mempunyai sebuah rencana anggaran, yaitu Daftar Isian Pelaksanaan Anggaran (DIPA) yang sudah ada di masing-masing BPS Kabupaten Kota. Berikut penuturan mbak Wahyu Eka Ningsih selaku Bendahara di BPS Kabupaten Sragen: "anggaran? Kalo rencana anggaran sudah tertuang di dalam DIPA mbak. DIPA sudah ada di masing-masing BPS Kabupaten Kota, terus dijabarkan lebih lanjut di POK”. DIPA adalah sebuah dokumen yang digunakan untuk pedoman dalam menggunakan anggaran yang telah disusun oleh Pimpinan BPS Pusat atau BPS Provinsi/Kabupaten/Kota yang telah disahkan oleh Direktur Jendral Perbendaharaan atas nama Mentri Keuangan, dan kemudian dijabarkan lebih lanjut pada POK (Petunjuk Operasional Kegiatan) yang berisi tentang rincian kegiatan dan jumlah anggaran yang telah disahkan oleh Kuasa Pengguna Anggaran (KPA). DIPA berfungsi sebagai dasar terkait pengeluaran negara dan pencairan dana.

\subsection{Perspektif Orientasi Pengguna}

Pada Perspektif Orientasi Pengguna, pengguna yang dimaksud disini adalah pegawai BPS Kabupaten Sragen. Seperti yang telah dijelaskan dalam Perspektif Kontribusi Perusahaan diatas, aplikasi maupun sistem yang digunakan oleh BPS Kabupaten Sragen dibuat oleh BPS Pusat. BPS Kabupaten Sragen hanya menerapkan aplikasi dan sistem tersebut sesuai dengan SOP yang telah dibuat oleh Pusat juga, dan sama sekali tidak terlibat dalam pembuatan aplikasi maupun sistem yang ada. Akan tetapi, aplikasi maupun sistem yang telah digunakan oleh pegawai BPS Kabupaten Sragen sesuai dengan kebutuhan yang diperlukan. Pegawai BPS Kabupaten Sragen tidak mendapatkan pelatihan dan pembelajaran untuk penggunaan aplikasi dan sistem tersebut, mereka diwajibkan untuk belajar mandiri dalam menggunakan sistem atau aplikasi yang ada. Berikut penuturan mbak Muhit Nur Hidayah selaku Staf Produksi : "Pelatihan untuk pakai sistem mbak? Enggak ada mbak, disini diwajibkan belajar mandiri. Jadi, harus bisa mengoprasikan sistem sendiri”. Namun, sistem yang digunakan terkadang mengalami error, salah satunya karena masalah jaringan internet, karena beberapa sistem harus terhubung dengan jaringan internet, dan jika pegawai tidak dapat memperbaiki error yang dialami pada sistem, BPS Kabupaten Sragen menghubungi BPS Provinsi, supaya BPS Provinsi dapat menyampaikannya kepada BPS Pusat untuk segera diperbaiki. Jika ditanya tingkat kepuasan pegawai terhadap sistem yang telah dibuat oleh Pusat, pegawai BPS Kabupaten Sragen cukup merasa puas dan sangat terbantu. BPS Kabupaten Sragen menyadari bahwa jaringan internet selalu saja dibutuhkan setiap saatnya dalam melakukan tugas dan kewajibannya, maka dari itu BPS Kabupaten Sragen berusaha menyediakan kualitas jaringan yang terbaik agar dapat menunjang kinerja pegawai, karena penjaminan mutu juga harus selalu dioptimalkan, bukan hanya untuk kenyamanan pengguna yang menggunakannya saja, akan tetapi untuk kenyamanan pegawai yang bekerja juga.

\subsection{Perspektif Penyempurnaan Operasional}

Pada Perspektif Penyempurnaan Operasional, kinerja pegawai sangatlah diperlukan, karena kinerja pegawai dapat berpengaruh terhadap kemajuan suatu perusahaan untuk kedepannya. Di kantor BPS Kabupaten Sragen terdapat 37 pegawai. Namun, pada saat ada kegiatan pengumpulan data melalui sensus dan survei, pegawai BPS Kabupaten Sragen dibantu oleh Mitra BPS untuk membantu tugas yang dikerjakan oleh pegawai. Pada saat pelaksanaan kegiatan Mitra BPS diberikan palatihan setiap akan menjalankan kegiatan yang akan dilaksanakan oleh BPS Kabupaten Sragen. Kriteria Mitra atau petugas setiap kegiatan di BPS Kabupaten berbeda-beda, tergantung pada jenis kegiatan yang akan dilakukan. Setiap tugas dan kegiatan yang dilakukan di BPS Kabupaten Sragen mempunyai dateline tugas masing-masing, tergantung pada besarnya jenis kegiatan yang dilakukan.

Salah satu kelemahan di BPS Kabupaten adalah pada jaringan internet. Jaringan internet adalah salah satu jenis layanan yang selalu saja dibutuhkan oleh semua pegawai di BPS Kabupaten Sragen setiap saatnya untuk melakukan pekerjaan. Namun, terkadang jaringan internet yang digunakan oleh BPS Kabupaten terkadang bermasalah. Berikut penuturan bapak Toga Hamonangan Nainggolan selaku Kepala di BPS Kabupaten Sragen : "ya terkadang memang bermasalah, karena tidak semua titik desktop atau atau leptop itu dapat kita sambungkan dengan kabel. Kalau dengan kabel biasanya lancar, tapi kalau dengan mempergunakan Wifi ya itu yang kadang bisa terputus dan lemot. Nah, memang ini kelemahannya, kelemahan dari bangunan ini itu tidak dilengkapi dengan konektivitas LAN yang cukup baik. Jadi, nggak mudah memang TI ini diadop oleh seluruh kantor yang ada di institusi. Bicara dimulut itu gampang tapi ternyata itu sangat sulit". BPS Kabupaten Sragen sudah lama berlangganan dengan Telkom Sragen terkait jarigan internet yang digunakan, dan menggunakan layanan internet yang levelnya paling tinggi. BPS Kabupaten Sragen selalu berupaya untuk selalu meningkatkan layanan internet yang digunakan dengan cara membangun komunikasi yang baik dengan pihak Telkom untuk mengatasi masalah atau gangguan yang muncul. Akan tetapi, bukan hanya soal masalah kualitas jaringan internet saja yang perlu diperhatikan dan dijaga. Namun, kondisi hardware dan software juga harus diperhatikan dan dijaga pula, karena 
software dan hardware juga berperan penting untuk menunjang kinerja pegawai di BPS Kabupaten Sragen. Software dan hardware merupakan suatu komponen yang tidak dapat dipisahkan. Di BPS Kabupaten Sragen jika ada hardware yang bermasalah atau rusak mereka segera memperbaiki, dan jika hardware sudah tidak bisa digunakan lagi mereka akan menggantinya dengan yang baru. Namun, jika software rusak atau error harus ditangani oleh BPS Pusat, karena software yang digunakan oleh BPS Kabupaten Sragen dibuat oleh Pusat.

\subsection{Perspektif Orientasi Masa Depan}

Pada Perspektif Orientasi Masa Depan, kualitas Sumber Daya Manusia (SDM), kualitas sistem atau aplikasi yang digunakan, dan kepuasan pegawai sangatlah diperlukan untuk kemajuan suatu perusahaan untuk kedepannya. SDM merupakan salah satu aset yang sangat berpengaruh terhadap perusahaan, karena kinerja pegawai sangat menentukan perusahaan sukses atau tidak dalam menghadapi persaingan yang semakin berkembang pesat dari waktu ke waktu. Di kantor BPS Kabupaten Sragen terdapat 37 pegawai di tahun 2019, yang terdiri dari Kepala BPS, 5 Staf Subbagian Tata Usaha (TU), 3 Staf Seksi Statistik Sosial, 3 Staf Seksi Statistik Produksi, 4 Staf Seksi Statistik Distribusi, 2 Staf Seksi Nerwilis (Neraca Wilayah dan Analisis Statistik), 2 Staf Seksi IPDS (Integrasi Pengolahan dan Desiminasi Statistik), dan 17 KSK (Koordinator Statistik Kecamatan). Jika ditanya terkait SDM di BPS Kabupaten Sragen, apakah SDM di BPS Kabupaten Sragen sudah tercukupi? "Belum, karena di BPS Kabupaten Sragen hanya mempunyai 17 Koordinator Statistik Kecamatan (KSK), sedangkan di Kabupaten Sragen ada 20 Kecamatan di Kota Sragen, dan disetiap Kecamatan harus ada KSK supaya segala macam informasi yang masuk bisa diketahui dengan detail" Ujar bapak Toga. Adapun penuturan bapak John Jaya selaku Staf IPDS terkait SDM di BPS : "Eeee, kalau dari segi kualitas sudah tercukupi, tapi kalau dilihat dari segi kuantitas masih kurang, karena disini hanya ada $17 \mathrm{KSK}$, sedangkan Kota Sragen mempunyai 20 Kecamatan. Jadi seharusnya di setiap Kecamatan ada KSK-nya".

Cara perekrutan pegawai di BPS Kabupaten Sragen ada 2 macam, yaitu perekrutan luar dan dalam. Perekrutan dalam dilakukan oleh BKN (Badan Kepegawaian Negara) yang bekerja sama dengan Kementrian Pendayagunaan Aparatur Negara dan Reformasi Birokrasi Republik Indonesia (Kemenpan RB) untuk melakukan rekrutmen pegawai melalui seleksi CPNS, sedangkan perekrutan dari dalam dapat langsung otomatis masuk, karena berasal dari Sekolah Tinggi Ilmu Statistik (STIS) yang dididirikan oleh BPS itu sendiri. Untuk perkrutan pegawai baru yang berasal STIS tidak ada yang namanya training atau pelatihan, karena sebelum mereka masuk dan ditempatkan, mereka sudah melewati proses magang di kantor-kantor BPS, tetapi jika untuk pegawai yang benar-benar baru, mereka diberikan pelatihan, namun pelatihan tersebut tidak bersifat khusus.

Kepuasan pegawai terhadap suatu perusahaan juga dapat berpengaruh pada kinerja seorang pegawai. Di BPS Kabupaten Sragen tidak ada yang namanya reward atau kompensasi berupa tambahan gaji yang diberikan kepada pegawai untuk pegawai yang dapat memenuhi target yang telah ditentukan. Karena di Pegawai Negri Sipil sekarang nggak ada sistem yang seperti itu ya. Jadi, yang namanya reward atau kompensasi tidak harus menggunakan tambahan gaji, bisa dalam bentuk perhatian. Karena memang semua pegawai sudah mendapatkan gaji, dan tunjangan" Ujar bapak Toga.

\subsection{Hasil Analisis IT Balanced Scorecard}

Perspektif Kontribusi Perusahaan pada BPS Kabupaten Sragen menjelaskan tentang Visi dan Misi, rencana strategi, dan pemanfaatan SI/TI. Visi dan Misi suatu perusahaan merupakan indikator dalam melakukan pekerjaan sesuai aturan yang telah ditentukan, dan mampu menjaga nama baik perusahaan dengan cara memberikan kenyamanan bagi semua pengguna. Pegawai BPS Kabupaten Sragen menyadari akan manfaat, dan pentingnya kehadiran SI/TI bagi suatu perusahaan, yang mana kehadirannya sangat membantu kinerja mereka karena yang mereka kerjakan semua berhubungan dengan SI/TI. Dengan dibantu oleh sistem maupun aplikasi yang telah dibuat oleh BPS Pusat di Jakarta, sangat membantu kinerja pegawai. Melalui hasil wawancara yang dilakukan, pada perspektif ini sudah terbilang baik, karena semua Misi yang telah ditetapkan telah dilaksanakan, dan dilakukan selaras dengan Visi yang akan dicapai dengan mengutamakan kualitas data yang diperoleh sebagai penyedia data dan informasi statistik.

Perspektif Orientasi Pengguna pada BPS Kabupaten Sragen menjelaskan tentang manfaat dalam penggunaan sistem maupun aplikasi yang ada. Sistem maupun aplikasi yang ada dibuatkan sesuai dengan kebutuhan pegawai di BPS Kabupaten Sragen. Tidak ada training yang dilakukan dalam penggunaan aplikasi maupun sistem, semua pegawai diharapkan dapat bekerja dengan mandiri. Akan tetapi sistem dan aplikasi yang digunakan terkadang mengalami error. Melalui hasil wawancara dan observasi yang dilakukan, pada perspektif ini sudah cukup baik, akan tetapi masih harus dilakukan perbaikan atau peningkatan pada jaringan internet karena beberapa sistem dan aplikasi yang digunakan oleh BPS Kabupaten Sragen harus terhubung dengan 
jaringan internet, sedangkan jaringan internet yang digunakan terkadang mengalami lambat koneksi dan terputus.

Perspektif Penyempurnaan Operasional pada Kabupaten Sragen menjelaskan tentang kontrol dan pengawasan diruang lingkup BPS Kabupaten Sragen. Dalam melakukan kegiatan atau tugas besar yang akan dilaksanakan, pegawai dibantu oleh mitra untuk dapat membantu mereka. Kualitas jaringan internet di BPS Kabupaten Sragen sudah cukup baik, begitu pula juga dengan keadaan software dan hardware, jika ada yang rusak segera langsung diperbaiki atau menganti dengan yang baru. Melalui hasil wawancara dan observasi yang dilakukan, pada perspektif ini sudah terbilang baik karena pengawasan dan kontrol selalu dilakukan oleh Kepala BPS Kabupaten Sragen dalam mengawasi dan mengontrol pegawai maupun diruang lingkup yang ada di BPS Kabupaten Sragen. Sehingga, proses penyelesaian tugas dan kewajiban yang dikerjakan tepat pada waktunya, sesuai dateline yang telah ditentukan.

Perspektif Orientasi Masa Depan pada BPS Kabupaten Sragen menjelaskan tentang SDM, yang mana SDM merupakan salah satu aset yang penting dan sangat berpengaruh terhadap kemajuan sebuah perusahaan baik sekarang atau dimasa depan. Tidak ada training dan pembelajaran untuk pegawai baru, serta tugas dan job desc yang diberikan juga sesuai dengan pengalaman dan kemampuan yang dimiliki, akan tetapi ada kalanya saling membantu antara pegawai satu dengan yang lainnya. Melalui hasil wawancara dan observasi yang dilakukan, pada perspektif ini terbilang sudah cukup baik, namun masih harus diperbaiki karena ada beberapa Kecamatan di Kabupaten Sragen yang tidak mempunyai KSK (Koordinator Statistik Kecamatan), maka dari itu perlu adanya penambahan SDM sebagai KSK untuk mengkoordinasi Kecamatan yang masih kosong.

\section{KESIMPULAN}

Dengan menggunakan kerangka IT Balanced Scorecard dapat melihat, menyelaraskan Visi dan Misi, dan juga dapat mengevaluasi serta melakukan pengukuran terhadap kinerja dari Pegawai. Berdasarkan hasil dan pembahasan dari 4 Perspektif dalam IT Balanced Scorecard pada penelitian ini, Perspektif Orientasi Pengguna, dan Perspektif Masa Depan yang dinilai harus perlu dilakukan perbaikan, karena pada Perspektif Orientasi Pengguna layanan SI/TI pada BPS Kabupaten Sragen selalu dibutuhkan setiap saatnya oleh pegawai di BPS Kabupaten Sragen untuk menyelesaikan tugas dan tanggung jawabnya sebagai seorang pegawai, serta untuk menunjang kinerja pegawai tersebut, dan pada Perspektif Masa Depan perlu adanya tambahan SDM, karena KSK di Kota Sragen pada saat ini hanya berjumlah 17 orang, sedangkan Kabupaten Sragen mempunyai 20 Kecamatan, dan seharusnya setiap Kecamatan mempunyai KSK untuk mewakili dimasing-masing Kecamatan.

\section{UCAPAN TERIMA KASIH}

Terima kasih disampaikan kepada kepala serta semua pegawai Badan Pusat Statistik Kabupaten Sragen yang telah mau menerima dan memberikan izin saya untuk dapat melakukan KP (Kerja Praktek) sekaligus melakukan penelitian di BPS Kabupaten Sragen, dan terima kasih juga disampaikan kepada Orang Tua, Kakak, Adik, Keluarga besar, serta teman-teman yang telah memberikan semangat dan dukungan pada saya, sehingga saya dapat menyelesaikan Laporan Tugas Akhir ini.

\section{DAFTAR PUSTAKA}

[1] Legoh, G. S., \& Tambotoh, J. J. C. (2015). Analisa Kinerja Sistem Informasi / Teknologi Informasi Pada BPPT dan PM Kota Salatiga Menggunakan Kerangka IT Balanced Scorecard ISBN : 979-26-0280-1 ISBN : 979-26-0280-1. 403-407.

[2] Wiyono, S., \& Tanaamah, A. R. (2018). Analisis Kinerja SI/TI Pada PDAM Kota Salatiga Menggunakan Kerangka IT Balanced Scorecard. Jurnal Buana Informatika, 8(4), 181-192.

[3] Molly, B., Tanaamah, A. R., \& Sitokdana, M. N. N. (2017). Jurnal Teknologi Informasi Dan Ilmu Komputer, 4(4), 318.

[4] Arofah, N. (2012). Penyusunan IT balanced Scorecard untuk pengukuran kinerja divisi IT di Pertamina UPMS V surabaya. Jurnal Teknik POMITS, 1(2), 1-9.

[5] Syarif, A. F., Basuki, P. N., \& Wijaya, A. F. (2018). Analisis Kinerja Sistem Informasi pada PT. Bank Central Asia Menggunakan IT Balanced Scorecard. Jurnal Nasional Teknik Elektro Dan Teknologi Informasi (JNTETI), 7(1). 